\title{
Pueblos minero-industriales y turismo cultural: una nueva relación en el sur de la pampa argentina
}

DOI: 10.22403/UQROOMX/TYP07/04

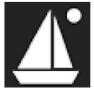

RESUMEN
Guillermina Fernández

Aldo Guzmán Ramos

Universidad Nacional del Centro de la Provincia de Buenos Aires

El presente artículo plantea la necesidad de revalorizar el patrimonio minero a través del turismo cultural, para fortalecer los recursos turísticos existentes y generar otros, con el propósito de desestacionalizar el turismo, potenciar su crecimiento, extender sus beneficios y preservar el patrimonio cultural, al tiempo que se aumenta su valor. Aquí se considerará el patrimonio mineroindustrial, representado por tres localidades ubicadas en la región sureste de la provincia de Buenos Aires, en la República Argentina, que están abandonadas o funcionan bajo lógicas y procesos espaciales diferentes de los que las gestaron. De tal forma, el turismo cultural podría hacer que recuperen su valor, con el significado histórico que poseen como patrimonio minero-industrial.

Palabras Argentina, patrimonio industrial, patrimonio minero, pueblos, CLAVE turismo. 
Pueblos minero-industriales y turismo cultural:

una nueva relación en el sur de la pampa argentina

\section{Introducción}

En la actualidad, la provincia de Buenos Aires, en Argentina, está generando acciones para fortalecer el turismo, apoyada en estrategias que mejoren la imagen de los recursos tradicionales de la región (sol y playa, eventos, agroturismo, etc.) e impulsen nuevos destinos (relacionados con actividades de aventura, agroturismo, turismo deportivo). En tal contexto, no se han considerado muchas otras modalidades de patrimonio cultural regional que pueden revalorizarse en el marco de un desarrollo sustentable de la actividad turística y que forman parte de la identidad de la región.

La región sureste de la provincia de Buenos Aires puede crecer y sustentarse como espacio turístico, para ello es necesario revalorizar, refuncionalizar y crear productos a partir del patrimonio minero-industrial localizado en ciertas comunidades, $y$ así desarrollar acciones para preservarlo y protegerlo.

El objetivo de este trabajo es proponer un nuevo producto turístico, aprovechando el patrimonio minero-industrial existente.

\section{Metodología}

Se seleccionaron tres comunidades minero-industriales del sureste de la provincia de Buenos Aires: Sierras Bayas, Cerro Leones y Villa Cacique, con el propósito de analizar su potencial para desarrollar el turismo cultural; el trabajo se fincó en técnicas de relevamiento, observación directa y entrevistas a informantes calificados. En la primera etapa se consideró sólo elaborar un diagnóstico del patrimonio tangible e intangible factible de revalorizar turísticamente, sin realizar estudios de aptitud de la población local hacia la actividad turística o análisis de mercado.

La metodología es cualitativa y las variables que vertebraron el trabajo de campo, o línea de base, fueron la originalidad, la diversidad de propuestas, el estado, la evolución histórica, etc. Estas variables fueron analizadas de forma individual y luego, evaluando los diferentes lugares, se generaron matrices comparativas entre los recursos y sus jerarquías, en lo que se denominó índice de jerarquía primaria (IJP), que se encuentra en fase de desarrollo.Adicionalmente, se describen los recursos que fueron seleccionados para la conformación de la matriz e índice, y una primera propuesta de articulación entre ellos. 


\section{El patrimonio cultural}

Pensar y definir qué es el patrimonio y qué implicaciones tiene es, sin lugar a dudas, una tarea compleja que comprende múltiples esferas que nacen de la manera en que los grupos sociales se relacionaron entre sí y con sus entornos de pertenencia. Es reflexionar sobre el modo en que la evolución de diversos procesos y formas de ser y hacer van adquiriendo significado para la propia sociedad en el tiempo.

Cuando nos referimos al patrimonio cultural de un país, región o ciudad hacemos referencia a todos aquellos elementos y manifestaciones tangibles o intangibles producidos por las sociedades, y que son resultado de un proceso histórico donde la reproducción de las ideas y del material constituyen factores identificatorios y diferenciadores.

Como sostiene Santana Talavera (2003: 5):

el patrimonio, relacionado con la herencia, es un concepto que alude a la historia, que se enlaza con la esencia misma de la cultura y es asumido directamente por los grupos locales. El patrimonio es la síntesis de los valores identitarios de una sociedad que los reconoce como propios. Ello implica un proceso de reconocimiento intergeneracional de unos elementos (desde el territorio a la ruina) como parte del bagaje cultural, y su vinculación a un sentimiento de grupo.

En ese instante, el objeto concreto estará a salvo, aunque sea momentáneamente, $y$, si bien su conservación no estará garantizada, al menos la sociedad sentirá como propia su destrucción y pérdida, por lo que se sentirá más involucrada. Ahora bien,

un concepto moderno de patrimonio cultural incluye no sólo los monumentos y manifestaciones del pasado (sitios y objetos arqueológicos, arquitectura colonial e histórica, documentos y obras de arte), sino también lo que se llama patrimonio vivo; las diversas manifestaciones de la cultura popular (indígena, regional, popular, urbana), las poblaciones o comunidades tradicionales, las lenguas indígenas, las artesanías y artes populares, la indumentaria, los conocimientos, valores, costumbres y tradiciones, características de un grupo o cultura [Casasola, 1990:31].

Este último constituye el patrimonio intelectual: es decir, las creaciones de la mente, como la literatura, las teorías científicas y filosóficas, la religión, 
Pueblos minero-industriales y turismo cultural:

una nueva relación en el sur de la pampa argentina

los ritos y la música, así como los patrones de comportamiento y la cultura que se expresa en las técnicas, la historia oral, la música y la danza.

Así, los elementos que constituyen el patrimonio cultural son testigos de la forma en que una sociedad o cultura se relaciona con su ambiente (Casasola, 1990). Son parte del sistema de objetos y relaciones que se configuraron en otro momento, $y$ adquieren valor para el conjunto de la sociedad actual, que se vincula a ellos de otra manera. Entonces, el patrimonio cultural se constituye por una porción del ambiente transformado incluyendo formas de organización social, relaciones entre los diversos sectores de la sociedad y de las instituciones sociales. Por otro lado, cada sociedad rescata el pasado de manera diferente, seleccionando de éste ciertos bienes y testimonios, los cuales están dotados de significado y son resignificados. El patrimonio, por ende, es el producto de un proceso histórico, dinámico, una categoría que se va conformando a partir de la interacción de agentes y situaciones, que obligan a tener una mirada a largo plazo, tanto en la concepción como en el uso de los recursos.

Por último, la información es un componente esencial del patrimonio. Saber cómo, cuándo y por quién ha sido utilizado un objeto enriquece nuestra comprensión del contexto humano del que procede. En ocasiones, la transmisión de esta clase de información es tan importante como la del propio objeto al que se refiere, de la cual se obtienen elementos clave para estimar su valor. Entonces, hablar de patrimonio es considerar a la cultura resultante de la interacción de la sociedad con el ambiente, donde se incluye el conocimiento, las aptitudes y los hábitos adquiridos por el hombre como miembro de una sociedad. Estas manifestaciones y elementos son un reflejo de la respuesta que el hombre da a los problemas concretos de su existencia y su relación con el entorno; esto es lo que lo hace válido para el desarrollo sustentable.

A continuación se abordará el tema del patrimonio minero-industrial. En un esquema amplio, podemos incluir dentro de él los inmuebles (áreas de extracción, zonas de producción, de vivienda, etc.) y los muebles (maquinaria, herramienta, archivos, etc.), aunado a los modos de vida de los trabajadores, el know-how (saber hacer) de los procesos productivos, entre otros elementos. Comprende un amplio abanico de manifestaciones que, espacialmente referenciadas, conjugan manifestaciones de procesos transformadores más 0 menos perdurables en el tiempo. 


\section{El patrimonio minero-industrial revalorizado a partir del turismo cultural}

El turismo se está convirtiendo en una fuente de ingresos muy importante para un elevado número de países. Pero este crecimiento, si bien genera divisas y empleo, también provoca una constante necesidad de aumentar la competitividad de los destinos turísticos. Por lo tanto, el turismo es una actividad en constante evolución, que trata continuamente de adaptarse a los requerimientos del mercado, el cual día con día eleva su exigencia y pide algo más que sol y playa, optando en ocasiones por un turismo cultural.

En este sentido, durante las últimas décadas ha crecido considerablemente el interés por este tipo de turismo basado en la cultura, $y$ dentro de éste ha surgido una particular atracción por los "restos" de la actividad minera e industrial, asociada a diferentes espacios.

Esta tendencia a considerar recursos turísticos los productos que incluyen la forma de vida y de trabajo generado por la actividad minera tiene carácter internacional, pero se ha desarrollado sobre todo en los países más avanzados como Japón, Estados Unidos, la Unión Europea, Canadá, etcétera.

Como ejemplo de esta nueva tendencia se encuentra el Ironbridge Gorge, que, con una superficie de $15.5 \mathrm{~km}^{2}$, es uno de los primeros museos al aire libre que persigue la recuperación del patrimonio histórico-industrial. Está situado en uno de los valles ingleses del río Serven, en el cual, durante el siglo XVIII existió una región con una importante actividad relacionada con la explotación de carbón y el comercio de hierro, siendo el mayor centro productor de hierro de Gran Bretaña. Hoy en día recibe más de 300000 visitantes al año, los cuales generan un ingreso aproximado de 50 millones de dólares estadounidenses (Puche, 1996: 12).

Es indudable que el desarrollo de este tipo de proyectos turísticos requiere el trabajo conjunto de antropólogos, arqueólogos e historiadores, además de especialistas en turismo y marketing, entre otros, quienes puedan explicar tanto los cambios que se han ido produciendo en el trabajo minero e industrial, como los procesos productivos, las relaciones sociales, la tecnología, etc., en los modos de vida dentro de la explotación y en las comunidades, permitiendo con ello comprender la cultura minera-industrial desaparecida y conocer las condiciones sociolaborales en las que se vivía. 
Pueblos minero-industriales y turismo cultural:

una nueva relación en el sur de la pampa argentina

De la mano de estas acciones se gestan los denominados ecomuseos, museos abiertos, parques culturales o rutas culturales, donde los elementos se encuentran in situ e incluso en funcionamiento, $y$ donde normalmente se puede apreciar también el trabajo manual y artesanal. Asimismo pueden convertirse en "manifestaciones u obras que combinan el trabajo del hombre y la naturaleza”, como ha planteado en su primer artículo la Convención Mundial de Patrimonio Cultural y Natural, al definir los paisajes culturales. De tal modo, las actividades mineras e industriales forman parte de transformaciones que configuran paisajes diferenciados que no sólo atestiguan la actividad extractiva sino los procesos industriales y las concentraciones de población asociadas.

En suma, estas formas de ser y hacer adquieren interés a partir de su propia definición y redefinición actual y pueden ser convertidas en recursos que complementen la oferta de servicios turísticos de una región o centro.

Esta reconversión y reutilización de elementos vinculados a la minería supone, en sus diferentes fases, evaluar su aptitud para convertirse en recursos turísticos y tener solvencia para potenciar tres elementos clave: mejorar su cualidad de atracción turística, su capacidad para vincularse al turismo y su accesibilidad espacial, legal y técnica. Los efectos positivos de la incorporación del patrimonio minero-industrial al mercado turístico pueden ser:

- Permitir la preservación, rehabilitación y puesta en uso de gran parte del patrimonio minero-industrial.

- Recuperar un testimonio del pasado, dado que las actuales condiciones sociales, técnicas, económicas, etc., son muy diferentes a las que regían cuando se desarrolló la actividad.

- Tener beneficios colaterales en aplicaciones prácticas, como la recuperación y rehabilitación de viviendas o cualquier otro tipo de bien inmueble de carácter tradicional, la creación o revitalización de museos o espacios temáticos, la definición y acondicionamiento de senderos naturales, la creación de centros de interpretación del patrimonio, el acondicionamiento de maquinarias antiguas, etcétera.

- Revitalizar o mantener, en parte, los oficios tradicionales relacionados con la explotación de las canteras, para la producción de suvenires, los cuales permiten al turista llevarse algo tangible del producto consumido.

- Dinamizar distintos sectores económicos, potenciando la actuación de grupos empresariales y bancarios en la rehabilitación de bienes inmuebles, 
muebles, etc. Tiene también un efecto multiplicador sobre el empleo, tanto directo como indirecto. En este sentido, puede significar la formación de profesionales en varios campos, desde la recuperación y revalorización de los recursos potenciales; el inventariado y la conservación y restauración de bienes patrimoniales de carácter cultural; el rescate de costumbres, tradiciones, oficios, manifestaciones festivas, etc.; la atención, protección y difusión de este patrimonio; hasta la promoción de productos y destinos turísticos que conforman, en conjunto, nuevas fuentes de empleo. Por otro lado, la recuperación de oficios puede permitir la reincorporación, aunque sea parcial, de personas de edad avanzada que necesiten trabajar (por distintos motivos) y que encuentren cerrado el mercado laboral actual.

A estos potenciales beneficios se deben agregar los posibles efectos negativos, porque ofrecer el patrimonio minero-industrial como atractivo turístico implica, de alguna forma, vender la cultura, por lo tanto es fundamental no banalizar el producto ofertado y conseguir, a través de técnicas de interpretación, que el turista comprenda la historia de lo que está viviendo.

Esto se puede lograr, sólo que es necesario que quienes ofrecen el servicio turístico tengan asesoría profesional adecuada. Es decir que, además de consultar a expertos en administración de negocios y marketing, también involucren a profesionales de las ciencias sociales que les ayuden a ofertar un producto turístico respetuoso del patrimonio, lo cual seguramente redundará en las posibilidades de éxito.

En una propuesta que incluya la recuperación del valor del patrimonio minero con criterios de sustentabilidad o sostenibilidad, no se debe priorizar la eficiencia económica por encima de la equidad social o el equilibrio ecológico, sino que debe primar el respeto hacia la cultura, donde la conservación de los rasgos tradicionales tiene que estar por encima de las expectativas del turista. De esta forma, aunque a veces las acciones sean mínimas, se garantiza un proyecto que no afecte aquello que le permite desarrollar su actividad económica.

En definitiva, la actividad minera, como dadora de elementos y manifestaciones espaciales patrimoniales, es potenciadora de la actividad turística, de la que puede obtener los recursos para su propia proyección y mantenimiento. Esto supone una revisión de la actividad primaria y de sus fases sucesivas con 
Pueblos minero-industriales y turismo cultural:

una nueva relación en el sur de la pampa argentina

criterios turísticos comprendidos en un proyecto sostenible, diagnóstico del cual resultarán las verdaderas aristas de una propuesta.

Por otro lado, y no menos importante aunque no desarrollada en estas líneas, está la necesidad de buscar redes sinérgicas que favorezcan procesos de complementariedad y que permitan la redistribución de esfuerzos y, sobre todo, el aprovechamiento de economías de escala.

\section{Los pueblos minero-industriales del sureste bonaerense}

\section{Pueblo de Sierras Bayas (Olavarría)}

Esta localidad, al contrario de otras de la pampa bonaerense que se fundaron por decisiones gubernamentales, se conformó a partir de agrupamientos de habitantes que rodearon, a finales del siglo XIX, las canteras y caleras que surgieron para explotar los recursos mineros de las lomadas que los nativos denominaron Sierras Bayas. Su patrimonio actual es variado. Una parte se ha incorporado en diversas estrategias de recreación y de acciones de política cultural local, pero otras aún no, aunque tienen potencial.

A continuación se describen los recursos jerarquizados y pueden ser revalorizados para el desarrollo del turismo cultural.

Museo Municipal de Sitio La Calera. Está situado en el centro de la localidad de Sierras Bayas. Su edificio fue construido en 1890 y se encuentra en muy buen estado. La calera, conocida como La Libertadora, comenzó a funcionar en 1906. Posee cuatro hornos verticales y un galpón con las bocas de los hornos, que dejaron de producir cal en 1984.

El museo de La Calera se inauguró el 5 de mayo de 2003, con el propósito de mantener la esencia de lo que fueron las caleras y de ilustrar a los visitantes sobre la forma de trabajar la piedra caliza, característica de la zona, hasta convertirla en la legendaria cal del Azul. Presenta intacta parte de la maquinaria del proceso productivo y herramientas usadas por los obreros. También existe en el lugar una muestra de carruajes antiguos y se presentan exposiciones itinerantes, por ejemplo de juguetes $u$ otros objetos.

Dentro de las actividades se han llevado a cabo ferias artesanales (cerámica, madera, tejido, etc.), muestras pictóricas de artistas locales y zonales, 
exhibiciones fotográficas e incluso un Taller de Historia Oral, con profesionales del Archivo Histórico de la Provincia de Buenos Aires, del Departamento de Patrimonio Cultural e Investigación Histórica de la Dirección General de Cultura y Educación de la Provincia de Buenos Aires y de la Universidad Nacional del Centro.

Horno inactivo Calera Victoria. Ubicado en Pueblo Arriba, perteneció a una de las familias de inmigrantes genoveses, los Arata. La calera y la cantera fueron explotadas desde 1906, en 1924 producían diariamente 45 toneladas de cal viva y 10 toneladas de cal hidráulica.

Además del horno, la casa, que en su momento fue delegación municipal y hoy en día funciona como escuela, da testimonio del patrimonio que ha sido legado. Por otra parte, entre 1927 y 1928 se construyó el Hotel Victoria, que luego se transformó en el Hotel Biagini, uno de los más importantes de la zona hasta mediados de siglo $\mathrm{XX}$.

En la actualidad, la calera está en ruinas y sólo se mantiene uno de los hornos, que se activa de manera esporádica. El horno, de eje vertical, en forma de botella invertida, es una estructura recubierta en ladrillo refractario que posee un plato removedor. Funcionaba para generar la cal viva, que luego era transportada por las vagonetas del ferrocarril a los sitios de acopio o molienda.

En el horno la piedra caliza es calentada a una temperatura tal que libera el dióxido de carbono, y la piedra se convierte en cal viva. El calor es generado principalmente por carbón de piedra o residual que puede ser colocado en capas entre la piedra caliza o mezclados con ésta.

Los hornos de eje vertical fueron diseñados para producción continua, donde la piedra, alimentada desde la parte superior, cae de forma gradual en la zona de cocción, luego en la zona de enfriamiento y al final es extraída por debajo, dejando sitio para realizar la siguiente carga y así sucesivamente. La capa superior es precalentada por los gases de evacuación y el aire que ingresa por debajo es precalentado por la cal viva en enfriamiento, obteniendo así el máximo uso del calor disponible.

No obstante que la Calera Victoria está abandonada, se puede recuperar el proceso productivo del horno y se encuentra dentro de la trama urbana. Los vecinos la consideran un emblema por el significado vinculado a los viejos procesos industriales. Tanto así que, en 1999, se organizó el programa Resignificaciones Públicas '99, en el cual se destacó el curso Todo es Collage, 
Pueblos minero-industriales y turismo cultural:

una nueva relación en el sur de la pampa argentina

en el cual se propuso El Muro de la Memoria, contiguo a la calera. En esta oportunidad, la población de Sierras Bayas fue protagonista, pues fue hasta el lugar para escribir en el muro aquellas cosas que no quería que cayeran en el olvido. Se empapelaron rocas a las que se les escribía un mensaje, lo cual dio forma a un muro por acumulación, cuya vida útil dependería del azar y del tiempo. Se escribieron 42 bloques y algunos de ellos quedaron como testigos del día en que se decidió recordar lo que eran y plasmarlo a modo de reafirmación, no de legado. Entre las cosas que surgieron están: “La memoria no es lo que recordamos sino lo que elegimos recordar. Somos culpables entonces del olvido"; "Un pueblo es el reflejo de toda manifestación de arte, si esto no fuera así éste perdería su identidad y sus raíces”;"Aún recuerdo el montacargas que funcionaba en esta calera para elevar vagonetas con piedras que alimentaban el horno... el motor del montacargas era a explosión..."

Otro proyecto del mismo programa se denominó Reubicando; en él un artista local tomó como idea tratar de reutilizar los residuos en la construcción de pequeñas estructuras de materiales desechados que fueron ubicadas en espacios públicos. El objetivo era contribuir a formar conciencia del cuidado y la conservación del medio ambiente, afirmando que los desechos se pueden transformar en un acto creativo, y no en basureros dispersos por el pueblo. El sitio elegido fue una pared del horno de cal, en la que aún hoy se aprecian algunas obras.

CALERA NASIF. Esta calera comenzó sus operaciones hace unos 60 años y las continuó hasta la década de los noventa. Se encuentra en total estado de abandono y posee restos que permiten recuperar de forma tangible e intangible todo el proceso de producción de cal. Tiene cinco hornos verticales, que funcionan igual al de la Calera Victoria, incluso con sus platos de zarandeo, sólo que con ventiladores para ayudar al proceso de combustión. El proceso productivo de generación de cal viva y luego cal apagada requiere diferentes etapas. El sistema presente en la calera cumple la siguiente secuencia, que puede ser observada casi en su totalidad:

a) Generación de cal viva en los hornos verticales, y almacenamiento a través de vagonetas en los silos de acopio.

b) Tratamiento de molienda en molino martillo, para la trituración primaria y secundaria de la roca. La característica principal de estos equipos 
es que trabajan a altas velocidades, las cuales provocan que, con la fuerza centrífuga, los martillos sujetos al eje del equipo sean dirigidos hacia afuera.

c) Tratamiento en batea hidratadora y batea mezcladora. El tipo de cal empleado para construcciones y otros numerosos procesos es la hidratada o apagada, la cual es obtenida añadiendo vapor o agua caliente a la cal viva. Las cales vivas puras reaccionan vigorosamente desprendiendo calor considerable, mientras que las cales impuras se hidratan lentamente, o sólo después de que los terrones son triturados. La forma más común es el hidrato seco, que es muy adecuado para almacenar en silos o bolsas herméticas y fáciles de transportar.

d) Silo de reposo. La cal permanece entre ocho y nueve horas en reposo.

e) Molino de bola. Se muele con bolas de acero de 10 a 12000 kilogramos de diferente tamaño en un sistema giratorio.

f) Separadores. Se envía desde el molino para el final del proceso; la cal fina va a acopio para embolsado, y la gruesa, salvo productos especíicos, vuelve al sistema para su reprocesamiento.

Esta estructura presenta una riqueza que puede redituar beneficios económicos a un proceso productivo singular, pero altamente enraizado en la identidad de más de diez empresas que operaron en la zona. Sus instalaciones pueden complementarse con al menos cinco canteras inactivas, algunas de las cuales han sido utilizadas como anfiteatro para presentaciones corales locales, y una cantera activa con explotación de dolomita ornamental (una de las únicas del país), que permitirían jerarquizar la oferta o cuando menos diversificar la propuesta.

\section{Asentamiento de Cerro Leones (Tandil)}

Enclave minero perteneciente a la ciudad de Tandil, está ubicado a 300 kilómetros de la ciudad de Buenos Aires, en un cordón serrano precámbrico, denominado sistema de Tandilia, rico en afloramientos de granito (roca de origen volcánico, compuesta de cuarzo, mica y feldespato), que es más duro que el mármol, lo que permite su pulido. El poblado de Cerro Leones lleva este nombre debido a que, como se comprueba por dibujos y fotos antiguos, allí existía una formación granítica que semejaba cabezas de leones, pero el trabajo 
Pueblos minero-industriales y turismo cultural:

una nueva relación en el sur de la pampa argentina

picapedrero transformó totalmente el espacio, sin dejar testimonios de las formaciones serranas.

La explotación minera comenzó en la década de 1870 con la llegada de inmigrantes sobre todo italianos y más tarde yugoslavos y españoles, entre otros. De esta inmigración quedaron vestigios en un importante patrimonio cultural tangible, como las viviendas, construcciones extremadamente sencillas de materiales como chapa, madera y piedra, con techos a dos aguas. Cada vivienda tenía un fogón para cocinar, por lo general hecho sobre el suelo, con dos filas de ladrillos o de piedras, y unos hierros transversales sobre los que apoyaban la olla de los guisos y pucheros. Cerca de sus casas muchos picapedreros tenían pequeñas huertas que construían en terrazas y que les permitían autoabastecerse de papa, zanahoria, zapallo, entre otros comestibles. Las terrazas ayudaban a retener el agua necesaria para los cultivos, práctica relacionada con las actividades agrícolas de los países natales de los trabajadores.

A lo anterior es posible agregar los restos de pircas o corrales de piedra -que alcanzaban un millar de metros de longitud y de medio a un metro de altura- construidos para encerrar a los animales; caminos de piedras que los picapedreros construyeron para transportar la roca desde el cerro; una gran cantidad de rocas con agujeros cónicos donde se insertaban los pinchotes para cortar las piedras mediante una técnica muy primitiva, y los bañiles, piletas de piedra perfectamente niveladas, con unos pocos milímetros de agua natural recogida en los manantiales donde se templaban las herramientas.

Junto a los restos de viviendas y elementos aledaños existían fondas habilitadas como almacenes $y$, al mismo tiempo, como centros de reunión de los trabajadores y sus familias. Por ende, constituyen testimonios de la vida social de los empleados de las canteras. En estos espacios se compartían juegos de naipes, de bochas, etc., y también música, pues casi todos tocaban algún instrumento (bandoneón, acordeón, guitarra, entre otros). De estos lugares se conservan dos: el Bar del Cerro, almacén de ramos generales de aquellos años, de chapa color verde con aberturas rojas y techo a dos aguas, que mantiene los rasgos de la edificación original, y frente a éste el Club Figueroa, fundado el 12 de octubre de 1922, donde aún se celebran fiestas y reuniones.

A estos restos edilicios se suma el patrimonio ferroviario, que tuvo un papel muy importante en el desarrollo de la actividad de las canteras. El ferrocarril llegó en I883, lo cual aumentó la producción minera de la localidad. Cerro Leones estaba unido a la ciudad por un ramal ferroviario que aún existe, 
aunque en un estado de abandono, pero que podría servir para llevar a cabo alguna actividad que reproduzca el transporte de piedra de la época.

Por último se añade un valor intangible, un elemento que marcó significativamente la vida y las luchas en las canteras: el pago con vales. Éste se efectuaba mediante las plecas, piezas fabricadas con distintos metales y acuñadas con caracteres distintivos de cada cantera, las cuales sólo circulaban dentro de cada establecimiento, lo que, de alguna forma, "esclavizaba" a los trabajadores. Las colecciones de plecas bien podrían constituir un museo de numismática, donde la comunidad asistiera para apreciar este valioso patrimonio local.

Como se observa, son elementos lineales y puntuales dotados de un considerable valor patrimonial, herencia de una etapa socioproductiva fundamental que los resignifica en conjunto y a partir de otros elementos intangibles.

Uno de los aspectos más importantes del patrimonio cultural intangible es la talla de la piedra, la cual era totalmente artesanal y se fundaba en el conocimiento intuitivo que tenían los picapedreros de la alineación cristalina de la piedra. El corte de la piedra en tamaños menores se hacía mediante una técnica muy primitiva, pero gracias a la destreza, observación y experiencia acumulada de generación en generación se había transformado en un acto de precisión casi rutinario: el método de los pinchotes o cuñas. Cada picapedrero diestro podía producir unos 250 adoquines por día o, en su defecto, entre 900 y I 000 granitullos diarios.

En la ciudad es posible observar restos de este trabajo en las calles adoquinadas y también en los bloques que revisten edificios, como los que pueden apreciarse en el Palacio Municipal, en la iglesia central, los colegios, etcétera.

El know-how de estos procesos productivos y sus adaptaciones y representaciones resultan de sumo interés en la comprensión de los cambios y mutaciones que la sociedad experimenta conforme se ajusta a las transformaciones (estructurales y tecnológicas) y deja que ciertas formas de "ser" y "hacer" perduren en el tiempo.

El trabajo de la piedra, de suma relevancia desde un punto vista patrimonial, puede ser rescatado y preservado. Existe un proyecto de la Dirección de Cultura del municipio, denominado Taller Municipal de Picapedreros y Escultura sobre Piedra, que funciona en un galpón del andén de carga de la estación de trenes. El objetivo es atraer a un variado público de todas las edades, interesado en aprender un oficio propio de la localidad: el trabajo artesanal y artístico de la piedra. Se busca promover y difundir el trabajo vinculado con la 
Pueblos minero-industriales y turismo cultural:

una nueva relación en el sur de la pampa argentina

utilización de materiales y técnicas tradicionales de las canteras, así como fomentar el conocimiento de esta actividad en el orden local y zonal, ofreciendo a la par una interesante perspectiva de desarrollo laboral. Por otro lado, es posible elaborar artesanías con técnicas tradicionales, las cuales pueden ser comercializadas en tiendas ambientadas según la arquitectura de la época.

Es igualmente importante su complementariedad potencial con Sierras Bayas, sobre todo en relación con las canteras de extracción de material ornamental, donde se comparte un proceso evolutivo del trabajo artesanal de la piedra por los inmigrantes, que otorga valor de replicabilidad.

Por otra parte, es necesario conocer la división del trabajo que se daba en las canteras y la organización político-ideológica que existía en ellas. Lamentablemente, si bien es posible rescatar y preservar la técnica utilizada en la explotación y tallado de la piedra mediante talleres, no es factible retroceder en el tiempo, excepto en un acto de recreación o tematización de las condiciones de la época. Por ello sería interesante crear un centro de visitantes, con fotos, cartelería, libros, diarios, y otros elementos más, donde se presenten y expliquen las características de los distintos oficios tradicionales, reuniendo en un espacio la información que hoy en día se encuentra dispersa. Asimismo, debería contar con datos sobre los oficios desarrollados en las canteras: picapedreros, barrenistas, herreros, marroneros, patarristas, foguines, zorreros, cuarteadores, vieros o arreglavías, peones, maquinistas, fogoneros y desgalladores.

En cuanto al protagonismo político e ideológico que desempeñaron los picapedreros, se debe reconocer que su organización fue pionera en el país. El 6 de octubre de 1906 se constituyó la Sociedad Obrera de las Canteras de Tandil, de orientación anarquista, lo que se comprueba por testimonios orales y por la militancia de su fundador Luis Nelli, quien fuera remplazado por Roberto Pascucci.Además de esta sociedad, en 1921 se creó la Agrupación Sindicalista de Tandil, a la cual podía ingresar "todo compañero organizado sindicalmente" que estuviese de acuerdo "con los métodos de la lucha de clases", como consta en actas de esta agrupación, que desapareció muy rápido (funcionó aproximadamente ocho años). Sobre estas organizaciones existe un importante patrimonio documental disperso en distintas bibliotecas públicas y privadas. Por desgracia, parte de estos documentos, como el periódico El Obrero Tandilense, desaparecieron por completo, producto de purgas político-ideológicas y del abandono de la organización gremial (aunque no se puede descartar que exista 
algún ejemplar en poder de alguna familia). Entre 1976 y 1978, un historiador local recopiló 64 testimonios orales de antiguos picapedreros, sus familiares y descendientes, lo cual constituye un acervo de patrimonio documental extraordinario.

\section{Pueblo-Fábrica de Barker-Villa Cacique (Benito Juárez)}

Ubicadas en una depresión tectónica del sistema serrano de Tandilia (formación sedimentaria), en el partido de Benito Juárez en el sureste de la provincia de Buenos Aires, a 60 kilómetros de la ciudad de Tandil y a casi 400 de Buenos Aires, las comunidades de Barker y Villa Cacique (en especial la última) son un ejemplo perfecto de un pueblo-fábrica, villa minera o comunidad de fábrica, nacida ex novo por razones estrictamente industriales $y$, además, ajenas a la dinámica económica de la zona en la que se enclava.

Como pueblo-fábrica ha sufrido una fuerte dependencia respecto de la actividad industrial que la originó. Por esta razón, la actividad económica de la empresa cementera, sus planes de expansión o sus crisis, marcan directamente toda la vida ciudadana, lo que se constata con precisión al comprobar que las construcciones fabriles y las urbanas han evolucionado en paralelo.

La historia de este lugar comienza a finales del siglo XIX, cuando se instaló una fábrica de cal perteneciente a la familia Vannoni, que producía cal con un horno, el cual al principio utilizaba leña como fuente energética y posteriormente carbón mineral. La materia prima se extraía de una cantera aledaña a la fábrica. Los principales destinos de lo producido eran Buenos Aires y Tandil, usando primero como transporte las carretas, y más tarde, en 1908, el ferrocarril, logrando así una comunicación más fluida.

A mediados del siglo XX (1955-1956) cerca de la calera se ubicó la fábrica de cemento Loma Negra, que al principio funcionó con un solo horno. En este periodo la población aún era escasa y una parte fue incorporada como personal de la planta (alrededor de 45 personas). Las primeras viviendas vinculadas a la planta fueron construidas por la empresa en 1954 y se destinaron al personal de mayor jerarquía.

En sus inicios, el proceso de producción de cemento era el denominado por vía húmeda: para su posterior cocido, entraba en el horno una mezcla de piedra caliza molida, arcilla y agua. Esto fue así hasta 1969-1970 cuando se instaló el método llamado por vía seca, consistente en la incorporación del polvo 
Pueblos minero-industriales y turismo cultural:

una nueva relación en el sur de la pampa argentina

seco, mezcla de arcilla, caliza y un agregado, que una vez cocidos permiten obtener el clinker. Este subproducto pasa por la molienda, donde se combina con yeso para conseguir el cemento.

A partir de la instalación del segundo horno en 196I, el requerimiento de mano de obra creció, por lo que comenzaron a llegar trabajadores de distintos puntos del país (Santiago del Estero, Catamarca, etc.) e incluso de naciones limítrofes (Bolivia o Chile, entre otros), sumando así 2000 empleados.

Al tiempo que la fábrica se expandía, generaba un crecimiento urbano importante, que podía observarse en la construcción de nuevos barrios y hasta de un centro comercial. (Si bien los negocios estaban en manos de concesionarios, tenían una fuerte relación con la empresa, que ejercía una especie de paternalismo sobre toda la población.)

Todo esto generó una comunidad de fábrica o pueblo industrial, pues la empresa fijó la fuerza de trabajo, construyó las viviendas de sus empleados, creó la infraestructura de servicios y todos aquellos elementos necesarios para la vida humana, por ejemplo el club social y deportivo, el balneario con canchas para practicar distintos deportes, piletas, fogones y más.

A partir de la década de 1980 se produjo un cambio significativo en la relación fábrica-sociedad: se comenzó el paso de un sistema de producción fordista hacia uno neofordista, con lo que se apunta a una mayor flexibilidad laboral y se empiezan a adoptar tecnologías modernas (informatización de ciertos procesos; mecanización de tareas, como la carga y descarga de material; etc.), que no serían suficientes, ya que, con el paso de tiempo, la tecnología aplicada a los procesos productivos de la planta resultó obsoleta.

Los cambios técnicos y organizacionales y la grave crisis económica de mediados de los ochenta, que se prolongó hasta los noventa, provocaron una paulatina reducción del personal (de I 060 empleados en 1974 a 80 al momento del cierre temporal de la fábrica), hasta llegar a menos de 60 trabajadores en la actualidad. Además de la pérdida de empleo, se desarticuló el espacio que se había conformado a mitad del siglo. Por ejemplo las "casas de la fábrica", que eran cabañas de alquiler mientras la fábrica estuvo cerrada, $y$ que ahora son utilizadas de nuevo.

Dada la importancia del funcionamiento de la fábrica y de su permanencia física, cabe plantearse la necesidad de una estrategia de rescate, a partir de nuevos aspectos tecnológicos y de otros usos del suelo que se llevan a cabo en la comunidad. 
Con base en estos criterios es menester destacar que la existencia del conjunto fabril, hoy patrimonio industrial, tiene diversos valores intrínsecos y extrínsecos que deben conservarse para ser conocidos por generaciones futuras, así como para resolver necesidades actuales de sus habitantes y conservar una conciencia de identidad y respeto por la historia del lugar.

\section{Propuesta de producto turístico}

Si no se actúa en consecuencia, la conservación del patrimonio minero-industrial de Sierras Bayas, Cerro Leones y Barker-Villa Cacique para su utilización turística es poco factible, por lo que es indispensable que se sostenga bajo un sentido de valor y de rentabilidad. En ese sentido, la inserción del patrimonio minero-industrial en un plan de desarrollo turístico regional puede ser una opción viable y efectiva, no sólo para lograr su conservación sino también para que, al momento de generar paulatinamente una estrategia de reactivación económica local, se beneficie por igual a los distintos sectores afectados por la reestructuración económica de las empresas industriales.

Este desafío debe enfrentar no sólo la visión indiferente de la comunidad respecto de la fábrica en su relación con el turismo, sino también la necesidad de apertura de las actividades económicas, activas o no, hacia un giro desconocido.

Al considerar las características de los elementos analizados es posible proponer una ruta que podría denominarse Recorriendo los pueblos mineroindustriales del sudeste bonaerense. Como la actividad minero-industrial adquiere diversas manifestaciones espaciales, tanto por su integración vertical u horizontal en diferentes circuitos productivos, como por la presencia de factores de localización que las agrupan bajo ciertos modelos de economías de aglomeración o de escala, a continuación se presenta el uso turístico-recreativo de los recursos culturales industriales a partir de la organización de rutas turísticas, teniendo en cuenta fundamentalmente que este mecanismo puede ser un motor de desarrollo local, tanto urbano como rural.

La ruta propuesta permitiría mostrar cómo se ha desarrollado la actividad minera desde su faceta tradicional hasta la actualidad, a través de la mecanización del proceso de extracción de la piedra y su manufactura, y también cómo se ha generado el proceso de transformación industrial. 
Pueblos minero-industriales y turismo cultural:

una nueva relación en el sur de la pampa argentina

El elemento más importante se relaciona con el efecto sociológico producido en la comunidad local por las empresas que actuaron asumiendo el control total desde un punto de vista económico, pero también influyendo en la vida privada y cotidiana de los pobladores de estas localidades. A partir de ahí es posible observar una idiosincrasia muy específica.

De acuerdo con el aprovechamiento que puede hacerse del recurso minero-industrial, éste se produce básicamente en los siguientes cinco grandes sectores:

I. Área de extracción: a cielo abierto, subterránea e instalaciones de apoyo.

2. Área de tratamiento del material: depósitos, lavado, clasificación,

3. Transporte: fluvial y marítimo o terrestre. En este caso las vías de ferrocarril son esenciales como vertebradoras del territorio; algunas de ellas desarticuladas o desmanteladas en la actualidad versus otras que aún están en vigencia.

4. Uso social y administrativo: viviendas de los trabajadores, equipamientos, oficinas, etcétera.

5. Zonas industriales: estructuras, maquinarias pesadas y livianas, entre otras.

Ahora se desarrollarán las características de la propuesta que puede activar, desde una perspectiva turístico-recreativa, los recursos minero-industriales de la región: rutas turísticas minero-industriales. En primer lugar, es indispensable definir qué es una ruta turística, cómo se constituye y quiénes la conforman. La ruta turística propuesta, con base en los lineamentos de Chan (1994), se compone de un conjunto de locales, en este caso de establecimientos industriales o mineros, o construcciones relacionadas con la producción, organizados en forma de red dentro de una región determinada y que, estando debidamente señalizadas, suscitan un reconocimiento de interés turístico.

La ruta se organiza en torno a un tipo de actividad industrial o minera que la distingue y le otorga su nombre; debe ofrecer a los visitantes una serie de placeres $y$ actividades relacionadas con sus elementos distintivos, $y$ debe presentar una imagen integral a partir de la complementariedad entre sitios, servicios, atractivos y lenguaje comunicacional.

La población local juega un papel clave:si ésta no tiene interés en una ruta cultural minera (paso siguiente a este trabajo), la posibilidad de éxito de un 
proyecto de desarrollo endógeno es casi nula. Por ello es primordial impulsar la participación social, pues si bien el proyecto estará guiado por expertos, debe considerar verdaderamente los intereses de la sociedad local para evitar la implantación de proyectos no deseados.

Esto supone, a priori, que una ruta turística es posible en la medida de su rentabilidad a corto, mediano o largo plazo, dependiendo de todos los intereses.

En este trabajo quedan por definir, en etapas subsiguientes, los actores reales, los ejes de desplazamiento y articulación, sobre todo los procesos de participación de los agentes y sectores de las tres comunidades.

La organización de rutas turísticas a partir de áreas y estructuras mineroindustriales puede permitir:

- Consolidar la cultura productiva regional: la identidad minera.

- Dinamizar las economías regionales y locales: respuesta al desempleo del sector en los tres sitios.

- Sensibilizar y concientizar sobre la importancia de la minería y la industria para recuperar la identidad de los pueblos: rescatar el valor histórico, sobre todo de la conformación de pueblos, villas y los procesos productivos artesanales prácticamente desaparecidos.

- Incorporar a los grandes circuitos nacionales otros circuitos turísticos ubicados en espacios marginados: complementariedad con el desarrollo turístico de la ciudad de Tandil, definida como puerta de entrada del turismo en la zona del sistema serrano de Tandilia.

- Preservar los restos de la actividad minero-industrial y dar a conocer condiciones de trabajo y procesos técnico-productivos, actuales y pasados: Taller del Picapedrero,Vagón de la Piedra (ambos en Tandil), Escuela de la Minería en Sierras Bayas.

- Promover el desarrollo productivo local a partir de un plan estratégico para los recursos minero-industriales y su valoración turística: desarrollar el Plan de Usos del Patrimonio Minero Industrial del Sistema de Tandilia en su conjunto, entre los tres municipios.

Cabe indicar que es necesaria una normativa para el funcionamiento y control de los elementos integrantes del proyecto, la que a su vez deberá contar 
Pueblos minero-industriales y turismo cultural:

una nueva relación en el sur de la pampa argentina

con una organización local que brinde información sobre la ruta, en la cual participarán personas relacionadas directamente con la actividad industrial y aquellas que no lo están.

Por otro lado, se debe pensar en el proyecto con un adecuado estudio de mercado -del actual que llega a la zona, sobre todo a Tandil-, y de sus ciclos estacionales, así como un sistema de promoción y uno de señalización de la ruta (que podría incluir un mapa con información sobre ella).

La alternativa presentada a continuación es una posibilidad dentro de todas las variantes que podrían crearse a partir de los recursos diagnosticados:

- Primero, en la localidad de Sierras Bayas, el visitante podría iniciar su recorrido en el Museo de La Calera, para conocer la historia y la forma de trabajo tanto minero como industrial de la zona; a continuación accedería a un horno inactivo y a una calera, cuya actividad comenzó a fines del siglo XIX, pudiendo observar también la maquinaria que con el paso de los años se fue incorporando.

- Desde Sierras Bayas el visitante tiene la opción de partir hacia la ciudad de Tandil y conocer la comunidad de Cerro Leones, donde apreciará la explotación de granito, material pétreo utilizado en innumerables calles y edificios de la ciudad de Buenos Aires. También puede observar los restos del patrimonio social legado por los picapedreros, como serían lo que queda de viviendas, huertas y las fondas, lugares donde los trabajadores se reunían para divertirse. El Club del Cerro brinda al visitante una imagen similar al de estos espacios frecuentados por los lugareños. Además, se puede conocer cómo era el proceso de trabajo manual de la piedra e incluso cómo se fueron produciendo los primeros movimientos sindicalistas en el país, por la presencia en ese entonces de trabajadores inmigrantes con ideales socialistas y anarquistas.

- Una vez que el visitante abandona esta localidad puede dirigirse a Barker-Villa Cacique que, con una estructura productiva moderna, permite observar en términos espaciales cómo se vivía la relación patrón-empleado en las fábricas del periodo fordista. Esta situación evidentemente ha cambiado por la transformación del modelo productivo, pero aún puede verse la diferencia en las áreas habitacionales destinadas a los trabajadores de distinto nivel jerárquico. 
Esta línea de base debe proyectarse en una propuesta donde los actores discutan la posibilidad de desarrollar el plan a partir de aquí, con las modificaciones y con los cierres y aperturas que se establezcan en consensos y negociaciones, $y$ asumida desde la complementariedad con las acciones implantadas tanto en el interior como en el exterior (en este último caso, tanto por el sector minero provincial, como por las acciones turísticas de cada comunidad).

\section{Reflexiones finales}

El desarrollo turístico del sureste bonaerense, basado en el turismo de sol y playa y en algunos otros atractivos tradicionales, implica una fuerte estacionalidad. No obstante, es posible generar un crecimiento significativo del turismo si se revaloriza el patrimonio cultural regional.

Obtener beneficios del patrimonio local como recurso turístico es un reto que debe ser controlado, planificado y gestionado de forma articulada entre el sector público y privado, para que pueda inscribirse en el marco del desarrollo sostenible.

El turismo potencia el desarrollo de las ramas de actividad que cubren directamente las necesidades de consumo de los visitantes (hotelería, gastronomía, comercio y servicios de ocio y recreación), pero también impulsa el desarrollo de otros sectores; aquí está la oportunidad. El turismo, debidamente planificado, puede incrementar de forma directa la renta de la población local, mediante salarios o beneficios empresariales.

Existe un patrimonio minero-industrial en el sureste bonaerense que puede aprovecharse y del cual es posible obtener ganancias, estimulando inclusive dinámicas culturales y asociaciones con otros procesos extractivos mineros y paisajes culturales de la minería. Aquí están las mayores fortalezas.

La revalorización y utilización turística del patrimonio cultural requiere la integración a un proyecto cultural donde la oferta, en función de los intereses de las comunidades locales, prime sobre la demanda y a su vez actúe de manera armónica.

Los puntos fundamentales de esta política deben ser la adecuada preservación, presentación y difusión del patrimonio minero-industrial y el entendimiento del turismo como una nueva forma de práctica cultural sustentada en el hecho de que todas las comunidades e individuos deben asumir que el 
Pueblos minero-industriales y turismo cultural:

una nueva relación en el sur de la pampa argentina

patrimonio cultural es un bien colectivo y como tal debe estar abierto al uso respetuoso de otros grupos sociales.

Por último, las posibilidades para desarrollar el turismo aprovechando el patrimonio minero-industrial tropiezan con una serie de limitaciones u obstáculos para este plan. La insuficiencia de recursos económicos y de financiamiento, la desvinculación de la población local en la gestión y valorización del patrimonio, la ausencia de planes y diseños turísticos en los que se compaginen el patrimonio con el desarrollo sostenible y la carencia de profesionales en turismo cultural, son los elementos de mayor debilidad encontrados.

Por esta razón, las autoridades municipales, junto con el gobierno provincial y el sector privado, deben generar los espacios de discusión para solucionar estas dificultades y buscar el camino hacia un desarrollo sustentable del turismo cultural en el sureste bonaerense, revalorizando el patrimonio mineroindustrial.

Son transformaciones espaciales del pasado que se manifiestan actualmente como estructuras y funciones que esperan ser interpretadas en un tiempo y un espacio presente y protegidas para ser testimonios en el futuro. Esto es más que un juego temporal.

\section{FUENTES CONSULTADAS}

Casasola, L. (1990). Turismo y ambiente. México:Trillas.

Chan, N. (1994). Circuitos turísticos. Programación y cotización. Buenos Aires: Librerías Turísticas.

Puche, O. (1996). "La conservación del patrimonio minero en Gran Bretaña". SEDPGYM, 5 (2), Madrid.

Santana Talavera, A. (2003). "Patrimonios culturales y turistas: unos leen lo que otros miran”. Pasos. Revista de Turismo y Patrimonio Cultural, I (I), I-I I. 